\title{
PROTEIN FOLDING IN THE CELL: The Role of Molecular Chaperones Hsp70 and Hsp60
}

\author{
F. U. Hartl and J. Martin
}

Program of Cellular Biochemistry and Biophysics, Rockefeller Research Laboratory, Sloan-Kettering Institute, 1275 York Avenue, New York, New York 10021

\section{W. Neupert}

Institut für Physiologische Chemie, Goethestrasse 33, 8000 München 2, Germany

KEY WORDS: stress proteins, chaperonins, GroE, catalysis of protein folding

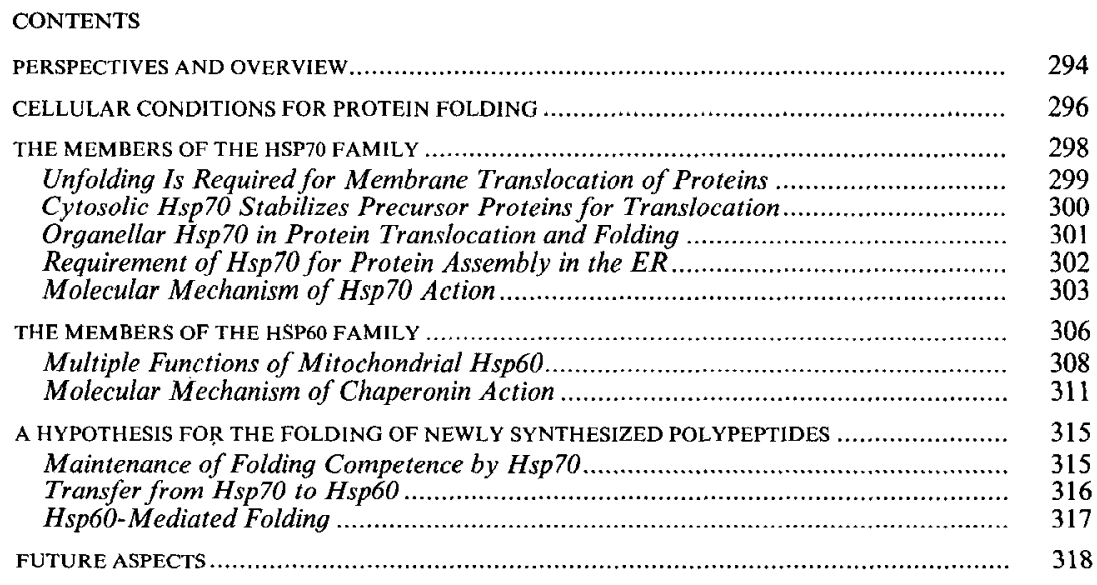




\section{PERSPECTIVES AND OVERVIEW}

The fundamental discovery that the amino acid sequence of a protein contains the full information specifying its native, three-dimensional conformation marked the beginning of an era of active biophysical research on the pathways and thermodynamics of protein folding (3). Many purified proteins when denatured to random coil-like structures can refold spontaneously in vitro. This action is driven by small differences in the Gibbs free energy between the unfoldcd and native states $(33,38,92,97)$. Consequently, researchers assumed that in vivo folding (acquisition of tertiary structure) and assembly (acquisition of quarternary structure) of newly synthesized polypeptides also occur by an essentially spontaneous process without the help of additional components.

Over recent years, however, several proteinaceous components have been discovered that directly influence the processes by which newly made proteins attain their final conformation within the cell. With the exception of the enzymes protein disulfide isomerase and peptidyl prolyl isomerase, which catalyze specific reactions that can be rate limiting for folding (reviewed in 53, 62, 63, 64), these components have been classified as molecular chaperones $(46,48,49)$ or polypeptide-chain binding proteins (168). They occur ubiquitously in prokaryotes and eukaryotes in the cytosol as well as within organelles (Table 1). Among the best characterized members of this heterogenous group of components are the constitutively expressed proteins of the Hsp70 and Hsp60 families (76). In the present context, their classification as stress- or heat-shock proteins may be somewhat misleading because these components are present in considerable amounts and fulfill essential functions under nonstressful conditions. Their expression can be induced under a great variety of cellular stresses, including heat shock, that may all have the accumulation of misfolded or partially denatured proteins in common. The term molecular chaperone initially referred to components such as nucleoplasmin $(39,106)$ and the chloroplast chaperonin Rubisco subunit binding protein (47), which assist in oligomeric assembly reactions presumably by preventing the formation of improper protein aggregates. The definition of molecular chaperone now includes the recently reported ATP-dependent functions of the various Hsp60s in actively guiding monomeric polypeptides to their native conformations.

This article summarizes the main lines of evidence that form the present view of Hsp70 and Hsp60 function in the folding and membrane translocation of newly synthesized proteins $(4,5,8,9,20,22,27,37,60,61,68$, $71,72,74,94,95,123,136,143,144,166,170,177,193,206)$. The basic principle of action common to Hsp70 and Hsp60 appears to be that they 
PROTEIN FOLDING AND CHAPERONES 295

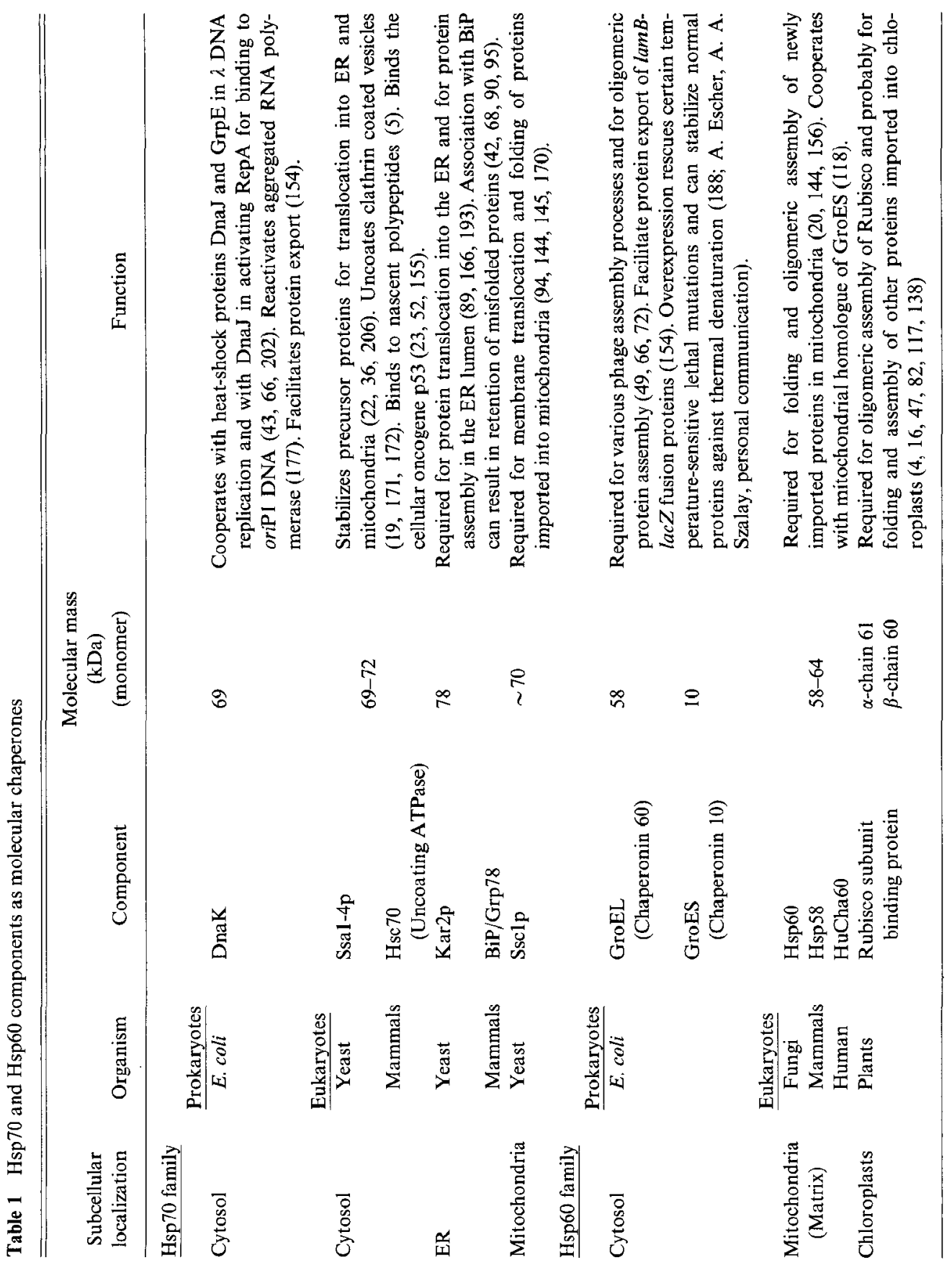


bind to segments of completely or partially unfolded polypeptides that are released upon ATP hydrolysis in an all-at-once or step-wise fashion. These chaperones can thus be involved in many cellular processes, preventing (premature) folding and aggregation, mediating correct folding, or stabilizing certain protein conformations. They may even rescue misfolded proteins by disassembling aggregates, or regulate the disposal of these proteins for degradation. Moreover, the general ability of binding and release shared by $\mathrm{Hsp} 60$ and $\mathrm{Hsp} 70$ can be utilized in various specialized processes such as clathrin uncoating and DNA replication. We discuss a model for the folding of nascent or newly translocated polypeptide chains based on their sequential and hierarchical interaction with $\mathrm{Hsp} 70$ and Hsp60. The function of the Hsp90 family of stress proteins in maintaining target proteins in inactive or unassembled states has been reviewed elsewhere $(29,198)$.

\section{CELLULAR CONDITIONS FOR PROTEIN FOLDING}

The main functional properties to be expected of factors assisting in physiological protein folding can be derived from a comparison between the conditions for folding in vitro and in vivo. Folding experiments in vitro are carried out with completely synthesized, artificially unfolded polypeptides $(33,53,92,97)$. Therefore, the same conditions apply equally to all parts of the folding polypeptide chain. The present concept of the sequence of events during refolding in vitro of an independently folding domain (usually about 100 amino acids) of a globular protein can be summarized as follows: As a result of the entropy-driven collapse of hydrophobic residues into the interior of the molecule, the multitude of random coil-like conformations present at high concentrations of denaturant converges within milliseconds towards the so-called prefolded state (23, 33,38 ). Secondary structure elements may form even prior to hydrophobic collapse but become stabilized only within the compact, prefolded conformation, thereby providing the framework for further folding $(33,97)$. Hence, this early folding intermediate already contains considerable nonrandom structure. It is believed to be similar to the molten globule or compact intermediate states described for certain proteins at intermediate concentrations of denaturant or at acid $\mathrm{pH}(23,102,157)$. These intermediates are in rapid equilibrium with the fully unfolded state. Within the compact intermediate (33), secondary-structure elements are then thought to become arranged in a slower process (extending over seconds to minutes) via a limited number of pathways, resulting in the formation of ordered tertiary structure. This process is accompanied by a further compaction of the polypeptide as it approaches the transition state of folding described 
as a distorted version of the native state. Importantly, progression from the prefolded state to the native structure depends on long-range interactions between secondary structure elements that appear to require the presence of at least a complete protein domain. For example, the deletion of even a few amino acid residues from either terminus of a polypeptide chain can prevent folding in vitro that kinetically favors misfolding and aggregation $(58,169,182,200,201)$. Independently folding domains are usually separated along the linear polypeptide chain frequently represented at the DNA level by distinct exons. However, this is not always the case; for example, the flavin adenine dinucleotide (FAD)-domain of glutathione reductase is composed of two noncontiguous parts of the chain that are 134 residues apart (173).

The fact that spontaneous folding of a protein is usually much faster than its synthesis in the cell (seconds as compared to minutes) implies that the folding of nascent chains is restricted, a characteristic of the situation in vivo (168). For example, when the synthesis of a polypeptide consisting of 100 amino acids is complete, 40 residues remain within the ribosome. Such a nascent chain will not be able to fold productively because only part of a folding domain is available. Instead, it may readily undergo intraand intermolecular aggregation. The prefolded state of a protein is thought to be particularly sensitive to aggregation because of the exposure of hydrophobic residues (33). One should bear in mind that the concentration of nascent polypeptide chains in the cytosol of a bacterial cell such as Escherichia coli can reach $50 \mu \mathrm{M}$, the concentration of ribosomes (35). The local concentration of nascent chains in a polyribosome complex might be even higher. Aggregation usually poses problems in refolding experiments at much lower concentrations of folding chains (130). As a result, folding in vitro often proves very inefficient, while folding in the cell is generally believed to occur with efficiencies close to $100 \%(130)$. Moreover, within the cell, proteins must fold in a highly viscous $20-30 \%$ protein solution (cytosol or intraorganellar space). Whether spontaneous folding in vitro is possible under such conditions is unclear.

Thus, polypeptide chains supposedly need to be protected against misfolding and aggregation during synthesis. The folding of a single-domain protein would not occur sequentially as the amino acid residues emerge from the ribosome but only when the complete protein is available, allowing the productive engagement of its structural elements in long-range interactions. Clearly, folding as the acquisition of the native tertiary structure must be a posttranslational process. In larger proteins, of course, an amino-terminal domain may already have engaged in folding while a more carboxy-terminal one is still being synthesized $(6,11,62,201)$. For example, influenza hemeagglutinin (containing multiple folding domains) was 
observed to acquire some disulfide bonds cotranslationally, but its final disulfide composition and antigenic epitopes are formed posttranslationally (11). With certain proteins, completion of the process of folding and assembly can take many minutes after synthesis $(26,85)$.

Polypeptide chains also encounter the problem of restricted folding during translocation across membranes. Proteins traverse membranes in an unfolded conformation and can only fold once translocation is complete. The following sections discuss the current concepts of how molecular chaperones mediate the formation of the native conformation by first preventing folding during synthesis or membrane translocation and then by mediating the step-wise, ATP-dependent release of polypeptide chains that results in folding. The proposed role of these components does not violate the principles of folding derived from biophysical studies with purified proteins. Rather, molecular chaperones may provide the means to translate these principles into action under physiological conditions.

\section{THE MEMBERS OF THE HSP70 FAMILY}

It may seem a paradox that efficient folding in vivo primarily requires antifolding activity, the prevention of folding during synthesis. Three lines of evidence suggest that stress proteins of the Hsp70 class interact with nascent polypeptide chains, maintaining them in loosely folded conformations: (a) Newly synthesized chains were found associated with constitutively expressed Hsp70 (Hsc70) in the cytosol of HeLa cells based on coimmuneprecipitation of the labeled proteins in cell extracts with antibodies directed against $\mathrm{Hsp} 70$ (5). (b) Cytosolic Hsp70 maintains precursor proteins destined for translocation across the membranes of endoplasmic reticulum (ER) or mitochondria in open, translocation-competent conformations $(22,37,206)$. Overproduction of DnaK facilitates protein export to the periplasmic space in E. coli (154). (c) Organellar Hsp70 on the trans side of mitochondrial and ER membranes binds to the incoming polypeptides $(94,145,170,193)$. This interaction is required for efficient translocation and for correct folding.

The members of the Hsp70 family have been highly conserved through evolution (Table 1). In addition to Hsp70s strongly inducible by heat shock and other forms of cellular stress, constitutively expressed Hsp 70s (Hsc70s) have essential functions under nonstressful conditions $(28,30,114,132$, 150 ). These proteins include the $E$. coli DnaK (66), the yeast cytosolic proteins Ssalp and Ssa2p (29) and the Hsc70 of mammalian cells, the socalled clathrin uncoating ATPase $(19,171)$. In addition, Hsp70s are found within subcellular organelles such as mitochondria (the Ssclp of yeast) 
$(31,32,110,131)$, chloroplasts $(2,122)$, and the endoplasmic reticulum (Kar2p in yeast and BiP in mammalian cells) $(74,133,134,143,166)$. These organellar Hsp70s contain typical amino-terminal targeting sequences directing their sorting to the correct membrane compartment. All Hsp70s appear to have the following structural and functional features in common: (a) They bind ATP $(19,60,96,199,207)$ and consist of a highly conserved amino-terminal ATP-binding domain ( $\sim 450$ residues) followed by a more variable carboxy-terminal substrate-binding domain $(19,54,96,143)$; $(b)$ they bind to unfolded or partially denatured polypeptides (147; J. M. Flanagan, G. C. Flynn, J. Walter, J. E. Rothman \& D. M. Engelman, submitted), and (c) they utilize the energy of ATP hydrolysis to release the bound substrates $(60,111,112,134)$.

\section{Unfolding Is Required for Membrane Translocation of Proteins}

The finding that proteins have to be unfolded for membrane translocation strongly stimulated cell biologists' interest in the mechanisms of protein folding in vivo $(45,80,128,160,203)$. For example, stabilizing the folded conformation of an artificial mitochondrial precursor by binding methotrexate to the passenger protein dihydrofolate reductase (DHFR) rendered the fusion protein unable to traverse the mitochondrial membranes (45). The import of mitochondrial proteins from the cytosol, which is essential for the biogenesis of mitochondria, occurs at so-called translocation contact sites where outer and inner mitochondrial membranes are in close proximity $(78,80)$. Fusion proteins with a sufficiently long mitochondrial protein part joined to DHFR could be accumulated as membrane-spanning translocation intermediates in contact sites (162). These precursors reach into the mitochondrial matrix with their amino-terminal targeting sequence, which is proteolytically cleaved, but leave the folded DHFR outside the organelle $(162,190)$. Less than 50 amino acid residues were sufficient to span the 18- to 20 -nm distance from outer surface of outer membrane to inner surface of inner membrane (163). The membranespanning sequences probably assumed a rather extended conformation. This is in agreement with the observation that urea denaturation of the precursor can speed up the translocation process considerably $(44,94$, 144).

These results may explain why a loosely folded conformation of precursor proteins is a general requirement for membrane translocation. But how is this state of translocation competence achieved? Because translocation, at least with mitochondria, is predominantly posttranslational (204), noncytosolic proteins could (a) either fold following synthesis and become actively unfolded prior to or during translocation, or $(b)$ be maintained in unfolded conformations as long as they are awaiting translocation 
in the cytosol. This latter mechanism applies to mitochondrial protein import and to posttranslational transport of proteins into the ER.

\section{Cytosolic Hsp70 Stabilizes Precursor Proteins for Translocation}

The presence of amino-terminal presequences retards the folding of purified precursor proteins as compared to their mature-sized counterparts $(107,160,161)$. Precursor proteins may thus efficiently interact with chaperones for prolonged periods. In the bacterial cytosol, several components including $\operatorname{SecB}(25,77,116,196)$, GroEL $(8,101,108,154)$, and the Hsp70 DnaK (154) stabilize precursor proteins, while in eukaryotes cytosolic Hsp70s (ct-Hsp70s) appear to be most important in this respect (36). $\mathrm{SecB}$, probably a pentamer of 15 -kilodalton $(\mathrm{kDa})$ subunits, binds to the presequence and the mature part of secretory precursors $(25,77,107$, 116, 196). Because SecB, in contrast to Hsp70 and GroEL, lacks ATPhydrolyzing activity, release from SecB appears to be accomplished by transfer of the bound protein to SecA, a peripheral ATPase of the translocation apparatus in the E. coli membrane (77).

Although binding of ct-Hsp70 probably also prevents folding in the case of nascent chains destined to remain in the eukaryotic cytosol (5), newly synthesized precursor proteins destined for membrane translocation provide more direct genetic and biochemical evidence for such a function (22, 36, 37, 136, 194, 206) (Figure 1, below).

The yeast Saccharomyces cerevisiae contains two genes coding for ctHsc70s (Ssalp and $S s a 2 p)$ and two coding for inducible ct-Hsp70s (Ssa3p and $S s a 4 p)(28,29)$. A yeast mutant in which $S S A 1, S S A 2$, and $S S A 4$ were disrupted was nonviable but could be rescued if transformed with a centromeric plasmid carrying the $S S A I$ gene under the control of the GALI promoter (37). When the cells were shifted from galactose-containing medium to glucose, the levels of ct-Hsc70s decreased, accompanied by the accumulation of precursor proteins destined to mitochondria and endoplasmic reticulum outside the organelles. The requirement of Hsp70 for protein translocation was also demonstrated in vitro using isolated microsomes and precursor proteins synthesized in a wheat germ lysate lacking functional $\mathrm{Hsp} 70$ (22). At least one further cytosolic activity was required, possibly for the release of the precursors from Hsp70 (136, 206). This activity could be inhibited by the sulfhydryl reagent $\mathrm{N}$-ethyl maleimide (NEM) (136). The eukaryotic cytosol may contain homologues of the bacterial heat-shock proteins DnaJ and GrpE, which in E. coli are known to cooperate with DnaK in phage $\lambda$ DNA replication $(43,66)$ by regulating the ATPase activity of DnaK (113). Whether DnaJ- and GrpE- 
like components are generally required by $\mathrm{Hsp} 70$ s to execute their various functions remains to be seen.

\section{Organellar Hsp70 in Protein Translocation and Folding}

MITOCHONDRIA The translocation of a folded protein domain, which has to lose at least all of its tertiary structure during membrane transport, can occur without a direct requirement for ATP or the membrane potential across the inner membrane (152). What then provides the energy for the vectorial movement of the polypeptide chain across the membranes? At low levels of ATP, the imported proteins are bound to the heat-shock proteins in the mitochondrial matrix, mt-Hsp70, and Hsp60 $(94,144)$ (Figure 1). Apparently, interaction with the mitochondrial Hsp70, Ssclp, is directly required for translocation $(94,145,170)$. In a temperaturesensitive yeast mutant affecting the gene coding for Ssclp, the transfer of precursor proteins into mitochondria was defective (94). Precursor polypeptides were arrested during translocation spanning outer and inner membranes at contact sites. This block could be overcome in vitro when the precursor was first unfolded using $8 \mathrm{M}$ urea and then rapidly diluted into a reaction containing the isolated mutant organelles. However, the precursor imported under these conditions remained in a highly proteasesensitive, incompletely folded conformation. Therefore, the mitochondrial Hsp70 apparently has a dual role in translocation and folding of imported proteins. Folding requires the transfer of the newly translocated polypeptides from mt-Hsp70 to Hsp60 (see below), a step that is blocked in the Ssclp mutant.

The energy resulting from binding of the extended amino terminus of the precursor protein to $\mathrm{mt}-\mathrm{Hsp} 70$ could be utilized to successively unfold parts of the precursor still outside the organelle (141). Multiple molecules of $\mathrm{mt}-\mathrm{Hsp} 70$ could bind to the traversing chain, thereby pulling it through the membrane. A typical precursor protein would be bound to cytosolic Hsp70 $(22,37)$. Both release from ct-Hsp70 $(153,206)$ and transfer of the imported polypeptide from mt-Hsp 70 to $\mathrm{Hsp} 60$ require ATP hydrolysis (F. U. Hartl \& T. Langer, unpublished data). In this model for the molecular mechanism of membrane translocation, multiple molecules of $\mathrm{mt}-\mathrm{Hsp} 70$ would bind with high affinity to the extended precursor polypeptide whose folding is restricted by the membrane. Fewer molecules of ct-Hsp70 would be associated with the precursor in the cytosol that has assumed the conformation of a collapsed prefolded state during or after synthesis.

ENDOPLASMIC RETICULUM The lumen of the ER contains an Hsp70 that was initially identified by its association with immunoglobulin heavy chains. This immunoglobulin heavy chain binding protein (BiP) $(9,74)$, 
also known as glucose-regulated protein Grp78 (134), is identical to yeast Kar2p $(143,166)$, which is inducible by various stress conditions including glucose restriction and the accumulation of secretory precursors. A temperature-sensitive KAR2 mutant shows a defect in translocation reminiscent of that seen in the mutation affecting the mitochondrial Hsp70 (193). At the nonpermissive temperature, precursors destined for the ER accumulated in the cytosol. Interestingly, Kar2p genetically and physically interacts with the Sec63 protein (167), a membrane component protruding into the ER lumen with a domain homologous to DnaJ. The defect in the KAR2 mutant could be reproduced using isolated microsomes of mutant cells and precursor proteins synthesized in vitro (R. Schekman \& M. Rose, personal communication). Surprisingly, translocation into reconstituted microsomes was observed even in the apparent absence of BiP (142). However, very small amounts of BiP that might have escaped detection could have been sufficient to accomplish the translocation of the small quantities of radiolabeled precursor protein.

\section{Requirement of Hsp70 for Protein Assembly in the ER}

In addition to its role in protein translocation, $\mathrm{BiP}$ has an important function in oligomeric assembly of proteins in the ER (89). In reviewing the results of the numerous studies analyzing the interaction of BiP with secretory proteins, our discussion focuses on those observations that are more directly related to protein folding. In fact, $\mathrm{BiP}$ was the first $\mathrm{Hsp} 70$ recognized as a polypeptide-chain binding protein because of its association with immunoglobulin heavy chains in pre-B cells (74). The heavy chains remain permanently bound to $\mathrm{BiP}$ in these cells and await the synthesis of light chains necessary for assembly of complete immunoglobulins $(9,85)$. Under various conditions leading to the accumulation of incompletely folded, modified, or nonassembled proteins in the ER, these proteins are detected as complexes with $\operatorname{BiP}(42,68,90,95)$. For example, mutated forms of the influenza virus hemeagglutinin, which cannot fold and assemble correctly, form stable complexes with BiP. In contrast, several normal proteins on the native folding pathway appear to interact only transiently $(68,89,95,100)$. The treatment of CHO cells with tunicamycin or exposure to glucose starvation causes the accumulation of undergylcosylated, misfolded proteins associated with $\operatorname{BiP}(42,109)$. Under these conditions, $\mathrm{BiP}$ is itself induced - hence the term glucose regulated protein Grp78 $(109,134)$. The primary stimulus for induction seems to be the presence of malfolded proteins rather than abnormal glycosylation (100). In addition to BiP, another stress protein of the ER, Grp94, is induced when incompletely folded or assembled proteins accumulate (100, 109). 
Bound proteins are released from $\mathrm{BiP}$ in a process requiring ATP hydrolysis (134). Metabolically poisoning cells to decrease the level of ATP prevented the trimerization of a mutant VSV G protein in the ER (41). Restoration of normal ATP levels allowed trimerization to proceed. These results indicated the existence of a pool of ATP in the lumen of the ER that had previously been unknown. The ATPase activity of purified BiP was found to be reduced in the presence of $\mathrm{Ca}^{2+}(96)$, raising the possibility that by modulating the level of $\mathrm{Ca}^{2+}$ in the ER, the capacity of $\mathrm{BiP}$ to retain newly made proteins could be regulated. Indeed, $\mathrm{Ca}^{2+}$ reportedly counteracted Mg-ATP-dependent release from BiP and secretion of variants of the T-cell antigen receptor $\alpha$ chain (179).

Secretory proteins must fold and assemble before leaving the ER through the secretory pathway. The main function of BiP could therefore be to retain normal proteins until assembly with other subunits is complete (84) or to prevent abnormal proteins from leaving the ER by channeling them into the ER degradation system $(90,98)$. However, BiP (up to 5\% of lumenal ER protein) is a soluble component. It leaves the ER with the bulk flow and is retained via its carboxy-terminal KDEL signal (HDEL in the case of $S$. cerevisiae Kar2p) by a recycling mechanism between a salvage compartment and the ER $(135,151)$. Whether BiP-bound proteins are retained by the same mechanism is unknown. BiP may well play a general role in folding and assembly of proteins newly translocated into the ER. Data indicating that $\mathrm{BiP}$ is required for the physiological folding of a monomeric protein are not yet available, however.

\section{Molecular Mechanism of Hsp70 Action}

SUBSTRATE RECOGNITION Hsp70s do not interact with defined sequence motifs. Their broad pattern of polypeptide recognition allows them to participate in many cellular processes. The affinity for certain substrates, however, may vary among the different members of the Hsp70 family. For example, clathrin cages stimulate the ATPase activity of cytosolic Hsc70 but not that of $\mathrm{BiP}(60)$. The principle of $\mathrm{Hsp} 70$ function is illustrated by the demonstration that various Hsp70s preferentially recognize short synthetic peptide sequences that may be exposed by unfolded or partially folded polypeptides. A first study using a few selected 10- to 15-residue peptides did not reveal any preference for a specific sequence or for a certain distribution of charge or hydrophobicity (60). Most peptides analyzed bound to $\mathrm{Hsp} 70$, but the binding affinities varied over three orders of magnitude. Recently, an extensive systematic study demonstrated that peptides of seven or eight residues optimally stimulated the ATPase of $\mathrm{BiP}(61)$. Consequently, the binding selectivity of $\mathrm{BiP}$ was tested using a mixture of randomly synthesized heptameric peptides. Sequencing the 
collective of bound peptides showed an enrichment of aliphatic amino acid residues (Val, Leu, Ile) and methionine at all positions of the bound peptide chains that was most pronounced within the region of the peptide core. Previously, Pelham $(148,149)$ proposed an interaction of Hsp70 with hydrophobic residues exposed by unfolded or partially denatured polypeptides. While most amino acids could be tolerated, charged residues and prolines, which are preferentially surface-exposed in native proteins, were excluded from the binding site (61). Random 7-mer peptides containing an average of 1.6 aliphatic residues bound efficiently to BiP. Coating by Hsp70 of the respective segments of nascent chains (statistically occurring every 16 residues in a globular protein) (61) might thus prevent (mis)folding and aggregation during synthesis and maintain the sequences emerging from the ribosome in an extended conformation (Figure 1). However, Hsp70s could probably hold a complete polypeptide chain of up to several hundred amino acid residues in a random coil-like state within a physiological environment. The protein might rather be stabilized in a collapsed prefolded conformation when some of the attached Hsp70 molecules (perhaps those bound with lower affinity) fall off either spontaneously or upon ATP-dependent release; other $\mathrm{Hsp} 70$ molecules would remain bound more firmly (Figure 1). After completion of synthesis, the protein would thus be stabilized in an open, perhaps molten globule-like conformation, the likely equivalent of the so-called translocation-competent state (15).

In the case of proteins that have already undergone folding to the native state but expose hydrophobic peptide segments because of denaturation, the free energy of Hsp70 binding could be utilized to resolve misfolding or aggregation. Such a function may be reflected by observations made with DnaK in a model reaction containing aggregates of thermally denatured RNA polymerase (177). Dependent on ATP-hydrolysis, DnaK present in at least stoichiometric amounts to RNA polymerase can dissolve the aggregates, resulting in reactivation of the enzyme. Certain native proteins might make use of surface-accessible, extended sequences to attract the attention of Hsp70. DnaK cooperates with the heat-shock proteins DnaJ and GrpE in specific disassembly reactions; for example, this occurs in bacteriophage $\lambda$ DNA replication by dissociating the DnaB protein from the $\lambda \mathbf{P}$ protein, which then allows the helicase to function $(40,43,66)$. Similarly, DnaK and DnaJ activate the RepA initiator protein that recognizes the origin of P1 replication by converting RepA dimers into monomers (202).

The three-dimensional structure of the carboxy-terminal domain of Hsp70, most likely responsible for specific substrate binding (19), has not yet been determined. However, molecular modeling based on a comparison of the carboxy-terminal domains of numerous Hsp70s from different 
sources suggested an interesting similarity with the $\alpha-1$ and $\alpha-2$ domains of the human major histocompatability antigen (MHC) class I protein (56, 165). One model proposes a peptide binding cleft for Hsp70 that, in contrast to that of the MHC class I molecule, would be lined predominantly by polar and charged amino acid residues (57). Another hypothesis predicts a peptide binding cleft containing both polar and apolar residues (165). This prediction seems plausible given that Hsp70 can accommodate both polar and apolar residues, possibly via interaction with the polypeptide backbone.

ATP HYDROLYSIS REQUIRED FOR RELEASE Although the binding of unfolded proteins or peptides to Hsp70 likely is independent of ATP, their release requires ATP hydrolysis by $\operatorname{Hsp} 70(24,60,61,84,111,134,207)$ and probably cooperation with additional factors such as DnaJ and GrpE or perhaps their homologues $(66,136,206)$. These heat-shock proteins stimulate the ATPase activity of DnaK (113). ATP hydrolysis, at least in the case of $\mathrm{BiP}$, may be regulated by $\mathrm{Ca}^{2+}(96,179)$. The binding of nucleotides can modulate the conformation of Hsp70 as revealed by changes in its sensitivity towards proteases (96). While ATP stabilizes Hsc70 in monomeric form, the presence of ADP favors the formation of dimers (172). The affinity of Hsp70 for ADP was found to be approximately sixfold higher than that for ATP. The ADP-bound form of Hsp70 also appears to associate with unfolded polypeptides more avidly. The release of the bound substrate could thus involve the exchange of ADP by ATP and its concurrent or subsequent hydrolysis (147). It is assumed that a conformational change of the amino-terminal ATP-binding domain of Hsp70 may be transferred to the carboxy-terminal substrate-binding domain, resulting in a decrease of binding affinity. Correspondingly, substrate binding stimulates the ATPase activity of $\mathrm{Hsp} 70(60,61)$.

The ATP binding and hydrolytic activity is contained in the approximately $44-\mathrm{kDa}$ amino-terminal domain of Hsp70 that is preserved upon limited proteolysis of the intact molecule $(19,96,143)$. The recent resolution to $2.2 \AA$ of the three-dimensional structure of the ATP binding domain of Hsc70 (54) revealed that its fold is almost identical to that of the globular monomer of actin (55). This observation is quite surprising because $\mathrm{Hsc} 70$ and actin share no sequence similarity. The structure of the nucleotide-binding site of $\mathrm{Hsp} 70$ is also similar to that of hexokinase (54).

The ATP requirement for release from $\mathrm{Hsp} 70$ is probably reflected in the dependence of protein translocation across subcellular membranes on cytosolic ATP $(80,128,189)$. The absence of ATP renders precursor proteins destined for mitochondria (153) and the ER (206) incompetent for membrane translocation. On the other hand, studies of the import of 
artificial precursor proteins into mitochondria that do not (or only weakly) interact with Hsp70 showed that translocation was independent of ATP (Figure 1) (152).

\section{THE MEMBERS OF THE HSP60 FAMILY}

Evidence indicates an active role in mediating protein folding for the members of the Hsp60 family of stress proteins (12, 20, 71, 72, 123, 127, 144). The Hsp60 components have been defined as a subclass of molecular chaperones termed chaperonins (83) (Table 1). They are found in the bacterial cytosol and in the inner compartment of chloroplasts (stroma) and mitochondria (matrix) $(49,76)$. Like certain Hsp70s, these proteins are constitutively expressed. While GroEL can be induced severalfold under heat-shock conditions, expression of mitochondrial Hsp60 is stimulated by heat stress only two- to threefold (20). The chaperonins also exhibit a weak ATPase activity $(18,123,192)$ but are structurally unrelated to the Hsp70s (except for a carboxy-terminal methionine-rich sequence of unknown function) (10). They form large tetradecameric complexes consisting of two stacked rings of seven $60-\mathrm{kDa}$ subunits each $(86,87,91$, 159).

The chloroplast chaperonin Rubisco subunit-binding protein was initially found associated with the newly imported small subunits and the chloroplast-encoded large subunits of ribulose bisphosphate carboxylase oxygenase (Rubisco) but not with the completely asscmbled enzyme (4, $16,47,137,138)$. This association was noncovalent and required ATP hydrolysis for dissociation. The Rubisco binding protein consists of distinct but sequence-related $\alpha$ and $\beta$ subunits that form mixed 14-mer complexes (82). The $61-\mathrm{kDa} \alpha$ subunit is $46 \%$ identical to the product of the groEL gene of $E$. coli (83).

The groEL gene is part of the groE operon that also contains the information for a smaller protein, GroES (also known as chaperonin 10). In its functional state, GroES exists as an oligomer (probably a heptamer) of 10-kDa subunits $(18,66)$. Various mutations in groEL and groES affect the assembly of $\lambda$ phage capsids but not cell growth of the host $(67,178$, $180,183)$. However, gene deletion experiments showed that both genes are essential for growth at all temperatures (51). The GroE proteins are the major heat-shock proteins of $E$. coli. The synthesis of GroEL can increase from a basal level of about $2 \%$ of total cellular protein at $37^{\circ} \mathrm{C}$ to about $12 \%$ at $46^{\circ} \mathrm{C}(140)$. Ample evidence suggests a physical interaction of GroEL and GroES as well as their involvement in folding and assembly of authentic and foreign proteins (66). Overexpression of the groE operon suppressed several heat-sensitive mutations, probably by maintaining the 
A

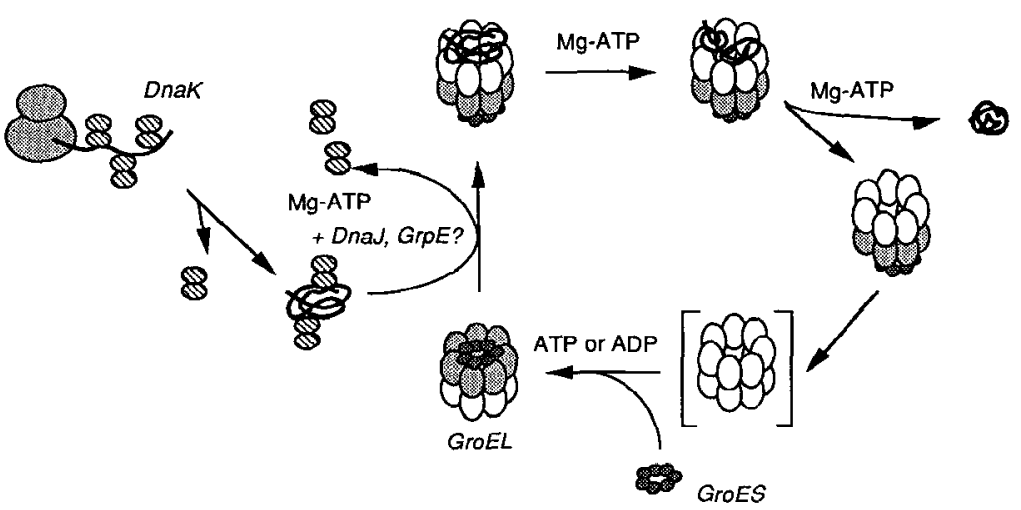

B

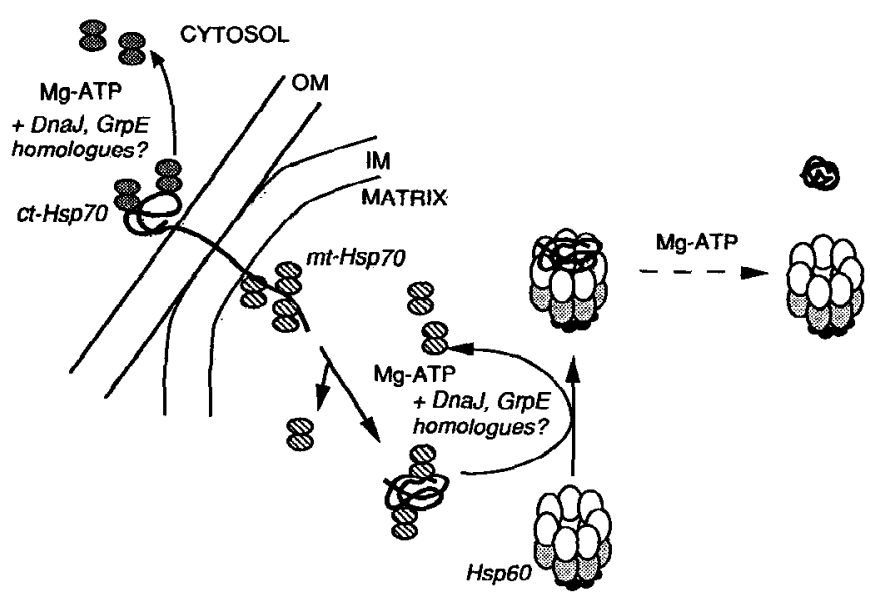

Figure 1 Hypothetical model for the differential function of Hsp70 and GroEL (Hsp60) in protein folding. (A) Folding in the bacterial cytosol. Nascent polypeptides interact with DnaK before reaching GroEL. Release of tightly bound DnaK may require the cooperation of heat-shock proteins DnaJ and GrpE. A single cycle of GroEL/GroES dependent folding is shown. Association with GroES may inhibit one of the 7-mer rings of GroEL for substrate binding (35). Whether top and bottom surfaces of GroEL are initially equivalent is unclear. Folding is assumed to occur by a surface-mediated process. Mg-ATP indicates the requirement for ATP hydrolysis. See text for details. $(B)$ Folding in the mitochondrial matrix. Newly synthesized precursor proteins are stabilized in a loosely folded conformation by cytosolic Hsp70 (ct-Hsp70). During and after membrane translocation, the polypeptides interact with mitochondrial Hsp70 (mt-Hsp70). Release from Hsp70 and transfer to Hsp60 for folding may require putative homologues of DnaJ and GrpE. See text for details. Abbreviations are: OM, outer mitochondrial membrane; IM, inner mitochondrial membrane. 
affected proteins in a functional conformation at the nonpermissive temperature (188). Increasing the levels of GroEL and GroES allowed the efficient assembly of heterologously expressed prokaryotic Rubisco (72). At wild-type levels of GroE, similar amounts of Rubisco were synthesized, but the newly made subunits could not assemble into the functional complexes. Overexpression of GroEL and GroES was also required for the functional expression of a thermolabile, heterodimeric luciferase at elevated temperatures (A. Escher \& A. A. Szalay, personal communication). GroE overproducers could become useful in the future to facilitate the biotechnological production of large amounts of foreign proteins in bacteria that often results in the formation of inclusion bodies $(88,130)$.

More recently, an $\mathrm{Hsp} 60$ was identified in mitochondria of Tetrahymena thermophila $(125,126)$ and in the mitochondria of various other species including humans $(93,131,164,195)$. The protein is synthesized constitutively as a cytosolic precursor and is assembled within the organelles. Hsp60 is coded for by an essential gene and constitutes roughly $1 \%$ of the total mitochondrial protein in yeast or Neurospora crassa under nonheat-shock conditions $(20,91,164)$. A homologue of the GroES protein exhibiting significant sequence similarity has been discovered in mitochondria (118) and is probably present in chloroplasts as well (A. Gatenby, personal communication). The chaperonins seem to be restricted to archaebacteria, eubacteria, and to organelles of endosymbiotic origin. However, a recent report states that a component of the eukaryotic cytosol, the TCP1 protein complex, is remotely related to Hsp60 (1) (see below).

\section{Multiple Functions of Mitochondrial Hsp60}

Mitochondria are a particularly suitable system for studying processes of physiological protein folding and assembly (76). In order to multiply by growth and division, these organelles have to import most of their proteins from the cytosol in an unfolded conformation $(78,80)$. Protein import and subsequent folding can be faithfully reproduced with isolated mitochondria and precursor proteins synthesized in vitro. Protein synthesis and physiological folding can be separated experimentally because of the posttranslational nature of the uptake reaction, a unique advantage of this system.

MONOMERIC CHAIN FOLDING AND OLIGOMERIC ASSEMBLY Evidence for a function of Hsp60 in protein assembly came from the analysis of the temperature-sensitive lethal yeast mutant mif4, which is defective in the MIF4 gene coding for Hsp60 (20, 21, 121; H. Koll, B. Guiard, J. Rassow, J. Ostermann, A. L. Horwich, et al, submitted). Because of a single amino acid substitution (A. Horwich, unpublished data), the altered Hsp60 under- 
goes a conformational change at the nonpermissive temperature that results in the loss of function. Proteins such as the precursor of the $\beta$ subunit of the $F_{1}$-ATPase or the trimeric matrix enzyme ornithine transcarbamylase are imported normally by the mutant mitochondria and are proteolytically processed, but cannot assemble into oligomeric complexes (20). The unassembled subunits have a tendency to aggregate in the matrix compartment.

The Hsp60 14-mer is also required for its own assembly (21). When wild-type Hsp60 monomers were expressed in mif4 mutant cells, they could not form a functional Hsp60 14-mer complex at the nonpermissive temperature. Thus, the machinery necessary for the folding and assembly of many if not most mitochondrial proteins cannot undergo self-assembly in vivo (21). On the other hand, a study of the (re)assembly of ureadenatured GroEL in vitro concluded that 14-mers are first formed spontaneously and then catalyze further assembly in a Mg-ATP dependent reaction (115). Self-assembly is also possible for GroES, at least under appropriate conditions in vitro (124).

A biochemical analysis of the interaction between imported proteins and mitochondrial Hsp60 revealed that the basic role of this chaperonin probably lies in mediating the folding of monomeric polypeptide chains (144). When the cytosolic protein mouse dihydrofolate reductase (DHFR) was imported into mitochondria as a fusion protein carrying a cleavable amino-terminal targeting sequence, its folding into the protease-resistant, native conformation occurred with a half-time of about $3 \mathrm{~min}$. This was much slower than import into mitochondria of the urea-denatured precursor. On the other hand, DHFR is known to fold rapidly in vitro (123, 184). This retardation of folding in mitochondria results from complex formation with Hsp60 (144). When the mitochondria used in the import reaction were depleted of ATP, the complex between DHFR and Hsp60 was stable and could be isolated from mitochondrial extracts. The Hsp60bound DHFR was highly sensitive towards digestion by proteinase $\mathrm{K}$, indicating that it was in an unfolded or incompletely folded conformation. ATP hydrolysis and an additional factor were necessary to allow folding of the Hsp60-associated protein. E. coli GroES can be substituted for this factor (118; F. U. Hartl \& A. L. Horwich, unpublished data). In the absence of the mitochondrial GroES, the ATP-dependent folding reaction slowed down, allowing the detection of a partially folded form of DHFR that was still associated with Hsp60 (144). Folding of DHFR in mitochondria could also be blocked by pretreatment of the organelles with NEM. Under these conditions, the DHFR fusion protein transiently associated with Hsp60 but then formed incorrectly folded aggregates. These results suggested an active function of $\mathrm{Hsp} 60$ in protein folding that 
is not simply explained by binding and release of the incompletely folded polypeptide (144) (Figure 1). The Rubisco subunit-binding protein probably has a similar role in the folding of proteins imported into chloroplasts or synthesized within the organelles $(117,156)$.

ANTIFOLDING IN PROTEIN EXPORT In addition to the functions in folding and assembly, Hsp60 is required for the export of certain proteins from the matrix to the intermembrane space of mitochondria $(20,78 ; \mathrm{H}$. Koll, B. Guiard, J. Rassow, J. Ostermann, A. L. Horwich, et al, submitted). For example, the cytosolic precursor of cytochrome $b_{2}$ is first imported completely and is then transported back across the inner membrane following a bacterial-type export pathway (79). This mechanism of intramitochondrial sorting is thought to reflect the endosymbiotic origin of mitochondria from prokaryotic ancestors (78). The information for export of cytochrome $b_{2}$ is contained in a hydrophobic amino-terminal signal sequence. Evidence that Hsp60 is involved in protein sorting to the intermembrane space again came from analyzing the Hsp60-deficient mutant mif4 (20). The mutant mitochondria accumulated incompletely processed forms of cytochrome $b_{2}$ and of the Rieske Fe/S protein, which follows a similar route to the intermembrane space (81). These findings suggested a role for $\mathrm{Hsp} 60$ in maintaining precursor proteins imported into the matrix in an open conformation competent for export across the inner membrane. A similar function in bacterial protein export has been observed with $E$. coli GroEL for a very limited subset of secretory precursors $(8,101,154)$, while the main chaperone for bacterial export appears to be $\operatorname{SecB}(25,77$, $116,160,161,196$ ).

How is the antifolding function of Hsp60 related to its role in mediating folding? A fusion protein consisting of the presequence of the intermembrane-space protein cytochrome $b_{2}$ and DHFR was imported into ATP-depleted mitochondria. A stable complex with Hsp60 formed in which DHFR was unfolded. Strikingly, the DHFR moiety could not fold when ATP was added. Folding occurred only after translocation to the intermembrane space had taken place (H. Koll, B. Guiard, J. Rassow, J. Ostermann, A. L. Horwich, et al, submitted). The hydrophobic export sequence may retard the folding of the mature protein part as demonstrated for certain bacterial secretory proteins such as the precursor of maltose binding protein $(160,161)$. Rebinding to Hsp60 following ATP-dependent release could be more rapid than folding, thus preserving an unfolded conformation of the protein. This possibility would be in agreement with results obtained by analyzing the interaction between pre- $\beta$-lactamase and GroEL in vitro $(8,103)$. A model of kinetic partitioning has been proposed to interpret the binding properties of secretory precursor proteins to SecB (75). In contrast to the chaperonins, SecB does not hydrolyze ATP. 


\section{Molecular Mechanism of Chaperonin Action}

To understand the molecular details of the mechanism by which the chaperonins mediate folding and assembly, one must reproduce their function in vitro using the purified components. The first important information came from studies reconstituting the GroEL- and GroES-dependent homooligomeric assembly of prokaryotic Rubisco (71). Rubisco subunits completely unfolded in $6 \mathrm{M}$ guanidinium chloride or denatured at acid $\mathrm{pH}$ were found to form stable binary complexes with GroEL, presumably as partially folded intermediates. This interaction prevented the aggregation of the protomers otherwise observed upon dilution from denaturant. ATP hydrolysis and the cooperating component GroES proved to be necessary for the formation of the assembled, biologically active enzyme (71). As discussed below, the Rubisco protomers likely underwent partial folding at GroEL and were ultimately discharged in a conformation competent for assembly with another subunit. Similar results were reported for the chaperonin-dependent assembly of dimeric citrate synthase (12), a protein whose refolding from denaturant had been unsuccessful so far. Recently, studies on the GroE-mediated refolding of monomeric dihydrofolate reductase $(123,191)$ and rhodanese $(123,127)$ shed new light on the mechanism of GroE action. Notably, all the in vitro studies consistently failed to provide evidence for a function of GroEL in refolding protein aggregates.

STABILIZATION OF AN EARLY FOLDING INTERMEDIATE The GroEL 14-mer complex appears to bind only one or perhaps two protein molecules, as demonstrated using various substrate proteins ranging in size between $\sim 20-50 \mathrm{kDa}(71,103,108,123,191)$. The stoichiometry of bound polypeptides per GroEL oligomer may increase with smaller substrates. One approach towards understanding chaperonin-mediated folding relies on (a) defining the conformation in which a protein substrate is stably bound by GroEL and (b) characterizing intermediates associated with the chaperonin during the folding process. The conformation of GroEL-bound DHFR from chicken and of bovine rhodanese were examined using fluorescence spectroscopy (123). Binding was performed by adding the substrate proteins from $6 \mathrm{M}$ guanidinium chloride to GroEL containing buffer in the absence of ATP hydrolysis. The intrinsic tryptophanyl fluorescence of the bound polypeptides was used to probe their tertiary structure. This approach was possible because both the sequences of GroEL and GroES lack tryptophans $(83,87)$. In both cases, the maximum wavelength of emission was at an intermediate position between that of the native and fully unfolded conformations (123). A marked increase in the fluorescence intensity, probably resulting from dequenching of $\operatorname{Trp} 24$, accompanied 


\section{2}

unfolding of DHFR. The GroEL-associated DHFR showed a fluorescence intensity nearly as high as DHFR unfolded in $6 \mathrm{M}$ guanidinium chloride, indicating that the conformation stabilized by GroEL lacked the specific tertiary structure present in the native protein. This observation was in agreement with the very high protease sensitivity of the GroEL-bound species $(123,191)$. Fluorescence quenching experiments showed that the tryptophans in GroEL-bound DHFR and rhodanese were better protected from solvent than in the fully unfolded conformations but significantly more accessible than in the native structures (123). These findings suggested that the GroEL-associated polypeptides were in a partially folded conformation perhaps similar to the molten globule $(23,34,102,158)$ or compact intermediate (33) states. An analysis of the binding of the fluorescent probe anilino-naphthalene sulfonate (ANS), whose fluorescence depends on the hydrophobicity of its environment, corroborated these results. Adsorption of ANS is typically observed with loosely folded protein conformations such as the molten globule $(23,157,158,175)$. Both GroEL-bound DHFR and rhodanese showed strong ANS fluorescence that was observed neither with the fully unfolded nor with the native proteins (123).

The nature of the structural elements recognized by GroEL is still unknown. Available evidence suggests that these elements are present in practically every protein whose interaction with GroEL has been tested so far. They could be extended peptide sequences, certain secondary structure elements, or conformational arrangements such as hydrophobic clusters or patches that would be transiently exposed by early folding intermediates resembling the molten globule. Using transferred nuclear Overhauser effect (NOE) measurements, Landry \& Gierasch (104) recently showed that a 13 -amino acid residue peptide representing the amino-terminal $\alpha$-helix of rhodanese binds to GroEL in an $\alpha$-helical conformation, albeit with low affinity. These investigators proposed that GroEL may recognize the hydrophobic face of amphiphilic $\alpha$-helices occurring at the amino terminus of nascent polypeptide chains (105). Assuming that the reported interaction was specific, these findings will be very important for eventually understanding the functional principle of GroEL in facilitating protein folding. The binding of secondary structure elements suggests a mechanism of action distinct from that proposed for the members of the Hsp70 family of molecular chaperones (see above).

FOLDING AT GroEL A molten globule-like conformation may represent the likely conformation of a polypeptide competent for translocation across membranes (15). The molten globule may also be the global conformation of newly synthesized proteins in which they enter the pathway of chap- 
eronin-mediated folding. Initiation of folding by $\mathrm{Mg}$-ATP and GroES resulted in the progression of GroEL-associated rhodanese to a more compact folding intermediate (123). This process was accompanied by a decrease in ANS fluorescence and an increase in intrinsic protease resistance. Similar results were obtained with folding of DHFR (123). These more compact intermediates were still bound to the GroEL double ring, suggesting that at least a partial folding reaction took place in very close association with the chaperonin.

The process of folding at the surface of GroEL depends critically on the presence of GroES. In the absence of GroES, ATP hydrolysis by GroEL appears to result in the complete release of the bound protein $(123,191)$. In DHFR, which folds spontaneously in vitro, this release was sufficient to allow the formation of the native structure. However, following complete release, DHFR could rebind to GroEL before completing folding, thus explaining why GroEL retarded the reactivation of DHFR as compared to the rate of spontaneous folding (123). In contrast, complete release in the absence of GroES did not lead to reactivation of rhodanese but rather to efficient cycling between the GroEL-bound and free states. Unlike DHFR, rhodanese cannot fold efficiently in vitro. Upon dilution from denaturant, the protein forms a collapsed intermediate that aggregates rapidly (181). This aggregation is prevented by binding of the rhodanese intermediate to GroEL $(123,127)$. The fact that complete release from GroEL in the absence of GroES did in fact occur could be proven using the pseudo-unfolded protein casein $(146,197)$ as a competitor for binding to GroEL. In the presence of Mg-ATP, casein displaced GroEL-bound DHFR or rhodanese (123). The released DHFR then folded spontaneously, while the fate of rhodanese was aggregation. Polypeptides folding at GroEL were protected from displacement by casein when GroES was present. Apparently during folding, the proteins were isolated from the bulk phase of the solution. According to these results, GroEL would have to interact with more than one segment of the protein substrate. Folding could occur by releasing these segments in a step-wise or sequential manner, a process that requires regulation by GroES (123). The substratebinding region of GroEL has not yet been identified. Binding to GroEL may occur at the central area of one of the 7-mer rings where all of its subunits could contribute binding sites for segments of the polypeptide chain, perhaps forming a kind of channel. Only one of the 7-mer rings may be active at a time for binding dependent on regulation by GroES (34).

The molten globule state during folding presumably adopts a progressively more compact packing of its secondary structure elements, resulting in the formation of ordered tertiary structure (102). We propose 


\section{HARTL, MARTIN \& NEUPERT}

that this reaction occurs by a mechanism of partial release while the protein remains in close association with GroEL. Unproductive interactions could be reversed, utilizing the energy of rebinding to GroEL, since these interactions would not allow the successful internalization of structural elements recognized by GroEL. Eventually, the protein would be set free in a conformation still before or already past the transition state of the folding pathway. In the case of oligomeric proteins such as Rubisco (71, 72 ), the monomers associated with GroEL are likely to assume the conformation of a folding intermediate able to associate with other subunits. Stabilization by GroEL would increase the concentration of this type of rate-limiting intermediate for the assembly reaction. It seems reasonable to assume that oligomerization takes place upon ATP-dependent release of the GroEL-bound monomers. Molecules that were unsuccessful in finding the proper partner to associate with could rebind to GroEL, thereby avoiding unwanted interactions.

Although how the chaperonins could increase the rate of an assembly reaction is evident, whether they actually catalyze the folding of monomeric polypeptide chains is unclear. Do the chaperonins mediate folding by lowering the activation energy of the productive folding pathway, or do they do so exclusively by raising energy barriers blocking pathways that lead to misfolding and aggregation?

ATP REQUIREMENT OF FOLDING Research has not formally shown that GroES may not interact directly with the polypeptide substrate folding at GroEL. According to the present view, however, the key to the function of GroES lies in its regulatory influence on the ATP-hydrolytic activity of GroEL $(18,123,192)$. The GroEL 14-mer probably has 14 ATP binding sites. In the absence of substrate, the GroEL complex exhibits a low but significant ATPase activity with a $K_{\mathrm{m}}$ for ATP of $7 \mu \mathrm{M}$ (192). This activity is almost completely suppressed by interaction with GroES at a 1:1 molar ratio of GroES 7-mer to GroEL 14-mer (123, 192). GroES and GroEL form an isolatable complex in the presence of Mg-ATP or ADP $(18,192$; A. Girshovich, unpublished data; J. Martin, unpublished data). Under the influence of GroES, the GroEL ATPase becomes strictly substrate dependent (123). In the case of rhodanese, approximately 100 molecules of ATP were hydrolyzed per protein molecule folded, suggesting that the GroEL 14-mer went through several cycles of ATP hydrolysis (123). The amount of ATP required for folding in vivo is unknown; one should keep in mind that the synthesis of a single molecule of rhodanese (293 residues) consumes roughly 1200 molecules of ATP, i.e. the ATP requirement for chaperonin-mediated folding will probably be a comparatively minor expense. 


\section{A HYPOTHESIS FOR THE FOLDING OF NEWLY SYNTHESIZED POLYPEPTIDES}

Recent findings for protein folding in mitochondria may suggest a principle mechanism for the acquisition of tertiary structure in vivo. Division of labor between molecular chaperones of the Hsp70 and Hsp60 families appears to be an integral element $(76,141)$. Although members of both groups of stress proteins interact with unfolded or incompletely folded polypeptides and utilize the energy of ATP hydrolysis for releasing the bound substrates, important functional differences are becoming apparent. Physiological folding of a newly synthesized polypeptide may occur by the following three-step reaction consisting of $(a)$ protection and maintenance of folding competence by Hsp70, (b) ATP-dependent transfer from Hsp70 to Hsp60, and (c) ATP-dependent folding at Hsp60 (Figure 1).

\section{Maintenance of Folding Competence by Hsp70}

Components of the Hsp70 family can associate with the folding polypeptide before those of the Hsp60 family, suggesting a hierarchy of interaction with molecular chaperones. For example, the mitochondrial Hsp70 binds to the extended protein sequences reaching into the matrix while they are still in the process of membrane translocation $(94,145,170)$. Similarly, cytosolic Hsp70 is thought to interact with nascent polypeptides emerging from the ribosome (5). Hsp70 binds unfolded peptide sequences $(60,61)$ and exhibits the highest binding affinities with mutant polypeptides that have little stable secondary structure (147; J. M. Flanagan, G. C. Flynn, J. Walter, J. E. Rothman \& D. M. Engelman, submitted).

The main purpose of the interaction of a nascent polypeptide chain with Hsp70 would be to prevent premature (mis)folding and aggregation of proteins (or their independently folding domains) during synthesis. It is unknown how many Hsp70 molecules could bind to a sequence of, say, 100 amino acids emerging from a ribosome (statistically containing perhaps up to 5 binding sites) (61). Binding of Hsp70 could prevent or retard the hydrophobic collapse of the molecule, and the emerging chain would transiently be held in a relatively extended conformation with little stable secondary structure. The initial binding may require the cooperation between Hsp70 and a DnaJ-homologous component. Because of its slow, ATP-dependent release activity, bound Hsp70 would fall off the substrate perhaps with kinetics adjusted to the speed of protein synthesis (60). This would allow the internalization of hydrophobic regions to a molten globule-like state now stabilized by fewer Hsp 70 molecules.

The interaction with Hsp70 alone appears not to be sufficient to promote the formation of ordered tertiary structure, at least in the case of proteins 


\section{HARTL, MARTIN \& NEUPERT}

imported into the mitochondrial matrix (94). The role of Hsp70 in protein folding could mainly consist of stabilizing the newly synthesized chains in loose conformations competent for the folding process mediated by a further component(s) or for membrane translocation (so-called "foldingcompetent" and "translocation-competent" states). Alternatively, the stabilization of nascent chains followed by cycles of ATP-dependent release and rebinding of Hsp70 may be sufficient for the folding of a subset of total soluble proteins that might contain sequence elements supporting the productive interaction with $\mathrm{Hsp} 70$. In fact, the existence of sequence information that ensures that a newly synthesized protein forms the correct intermediate conformations on the folding pathway was demonstrated by the mutational analysis of the in vivo folding of P22 tailspike polypeptide $(69,70,129)$. This information is not required to stabilize the native state of the protein. Because of coevolution with molecular chaperones, proteins may contain structural elements directing the programmed interaction with these components.

\section{Transfer from Hsp70 to $\mathrm{Hsp} 60$}

Folding in mitochondria appears to depend on the newly imported proteins being transferred from Hsp70 to Hsp60 $(94,144)$. Very little is known about this transfer reaction. In light of the finding that binding of Hsp70 is necessary for membrane translocation, while Hsp60 function appears to be of little importance at this stage $(94,144)$, transfer to Hsp60 should occur when import of the protein (or its domains in case of larger polypeptides) is complete. Other mitochondrial components, perhaps similar to the NEM-sensitive factor contained in reticulocytc lysates (136), may have to cooperate with $\mathrm{Hsp} 70$ to ultimately allow its complete release from the imported protein. Natural candidates could be mitochondrial homologues of E. coli DnaJ and GrpE that are known to physically interact with the Hsp70 DnaK (66). Homologues of DnaJ have been reported for mitochondria (7), for the yeast nucleus (17), and for the cytosol $(17,119)$. In addition to their roles in DNA replication $(43,66$, 202), DnaJ, DnaK, and GrpE have as yet undefined functions of general importance for normal growth of $E$. coli $(13,14,66,174)$ that may include protein folding (65). DnaK is dispensable at intermediate growth temperatures around $30^{\circ} \mathrm{C}$ (although the cells grow very poorly) and becomes essential for growth at temperatures below and above $30^{\circ} \mathrm{C}(13,14)$. At present, all results would be compatible with DnaK having a critical buffer function in protein folding, holding and protecting nascent chains until they can be taken over by GroEL. Under non-heat-shock conditions, cells would contain fewer GroEL molecules than nascent chains; the basal level of the GroEL 14-mer is about $15 \mu \mathrm{M}$, while the concentration of nascent 
chains is $30-50 \mu \mathrm{M}$ and that of DnaK is $100 \mu \mathrm{M}$ (calculated according to refs. $35,73,139)$. Furthermore, GroEL may bind nascent chains only at a later stage of synthesis than DnaK and would therefore be unable to efficiently prevent their aggregation. This lack of protection would become more critical at higher growth temperatures. We propose that DnaK, DnaJ, and GrpE cooperate with GroE/GroES in the de novo folding of proteins.

\section{Hsp60-Mediated Folding}

Evidently, Hsp70 cannot assume some specific functions of Hsp60 in protein folding. The chaperonins appear to mediate folding by a process of step-wise release while the folding polypeptide remains sequestered at their surface $(123,144)$. Surface-mediated folding may critically depend on an oligomeric machinery in which the individual Hsp60 monomers contribute binding sites for polypeptide segments whose action would be coordinated in the oligomeric chaperonin complex.

Although both mitochondrial Hsp60 and E. coli GroEL/GroES fulfill essential functions under all growth conditions (51), it is unclear what percentage of total proteins depend on chaperonins for folding. Given the importance for protein folding we assign to Hsp60, one would expect that chaperonin-like components were present in every cellular compartment capable of de novo folding. A functional equivalent of Hsp60 in the eukaryotic cytosol has not been found so far, but a remote structural homology to GroEL and mitochondrial Hsp60 has been reported for the TCP-1 protein complex (1), which led to the proposal of a molecular chaperone function for TCP-1 (49), a high-molecular-weight complex similar in size to that of the chaperonins (V. Lewis \& $\mathrm{K}$. Willison, personal communication). TCP-1 was originally described as involved in the phenomenon of male-specific transmission ratio distortion in mice (120, 176). The protein is abundantly expressed in developing sperm, but a more general function is suggested by the detection of TCP-1 in the cytosol of all other cell types analyzed to date $(186,205)$. A cold-sensitive mutation in yeast affecting TCP-1 impairs mitotic spindle formation (187). The recent discovery of the thermoprotection factor TF55 of the thermophilic archaebacterium Sulfolobus shibatae makes TCP-1 a very attractive candidate for an Hsp60-like function in the cytosol (185). TF55, the major heat-shock protein of $S$. shibatae, appears to be an 18-mer complex of 55$\mathrm{kDa}$ subunits with $\sim 40 \%$ sequence identity to TCP- 1 of mouse and yeast (185). These findings may support speculations on the existence of two evolutionary lines of chaperonins, one leading from eubacteria to mitochondria and chloroplasts and the other leading from archaebacteria to the eukaryotic cytosol. 


\section{FUTURE ASPECTS}

It is now generally accepted that protein folding in the cell needs mediation by molecular chaperone components. Despite considerable advances towards understanding the function of Hsp70 and Hsp60, many aspects of their molecular mechanisms of action are still unclear. We are just beginning to understand how unfolded proteins are recognized and how their folding is prevented or promoted. In no case is the structural basis for binding fully established. While at least a partial crystal structure of Hsp70 is available, such information is completely lacking for the Hsp60 components. Remaining questions include: How is ATP hydrolysis transformed into conformational changes of the chaperone, ultimately resulting in folding of the protein substrate? Or, from a more cell-biological point of view, what is the exact sequence of interactions with chaperones during and following synthesis of a polypeptide chain? Can these processes, for example the functional cooperation between Hsp70 and Hsp60, faithfully be reproduced in vitro? Given the significance and the current interest in aspects of protein folding in vivo, we will probably not have to wait long for the answers to many of these questions.

\section{ACKNOWLEDGMENTS}

We thank D. Engelman, J. Flanagan, A. Gatenby, A. Girshovich, A. Horwich, V. Lewis, G. Lorimer, J. King, M. Rose, J. Rothman, R. Schekman, A. Szalay, and K. Willison for sharing unpublished information, and A. Horwich for stimulating discussion. Work in the authors' laboratories was supported by the Deutsche Forschungsgemeinschaft.

\section{Literature Cited}

1. Ahmad, S., Gupta, R. S. 1990 . Biochim. Biophys. Acta 1087: 253-55

2. Amir-Shapira, D., Leustek, T., Dalie, B., Weissbach, H., Brot, N. 1990. Proc. Natl. Acad. Sci. USA 87: 1749-52

3. Anfinsen, C. B. 1973. Science 181: 223 30

4. Barraclough, R., Ellis, R. J. 1980. Biochim. Biophys. Acta 608: 19-31

5. Beckmann, R. P., Mizzen, L. A., Welch, W. J. 1990. Science 248: 850-54

6. Bergman, L. W., Kuehl, W. M. 1979. J. Supramol. Struct. 11:9-24

7. Blumberg, H., Silver, P. A. 1991. Nature 349: 627-30

8. Bochkareva, E. S., Lissin N. M., Girshovich, A. S. 1988. Nature 336: 25457
9. Bole, D. G., Hendershot, L. M., Kearney, J. F. 1986. J. Cell Biol. 102: 1558 66

10. Bosch, T. C. G. 1991. In Heatshock, ed. S. Lindquist, B. Mareska. Heidelberg: Springer Verlag. In press

11. Brackman, 1., Hoover-Lefty, H., Wagner, K. R., Helenius, A. 1991. $J$. Cell Biol. 114: 401-12

12. Buchner, J., Schmidt, M., Fuchs, M., Jaenicke, R., Rudolph, R., et al. 1991. Biochemistry 30:1586-91

13. Bukau, B., Walker, G. C. 1989. J. Bacteriol. 171: 2337-46

14. Bukau, B., Walker, G. C. 1990. EMBO J. 9: 4027-36

15. Bychkova, V. E., Pain, R. H., Ptitsyn, O. B. 1988. FEBS Lett. 238: 231-34 
16. Cannon, S., Wang, P., Roy, H. 1986. J. Cell Biol. 103: 1327-35

17. Caplan, J., Douglas, M. G. 1991. J. Cell Biol. 114: 609-21

18. Chandrasekhar, G. N., Tilly, K., Woolford, C., Hendrix, R., Georgopoulos, C. 1986. J. Biol. Chem. 261: 12414 19

19. Chappell, T. G., Konforti, B. B., Schmid, S. L., Rothman, J. E. 1987. J. Biol. Chem. 262: 746-51

20. Cheng, M. Y., Hartl, F. U., Martin J., Pollock R. A., Kalousek F., et al. 1989. Nature 337: 620-25

21. Cheng, M. Y., Hartl, F. U., Horwich, A. L. 1990. Nature 348: 455-58

22. Chirico, W. J., Waters, G. M., Blobel, G. 1988. Nature 332: 805-10

23. Christensen, H., Pain, R. H. 1991. Eur. Biophys. J. 19: 221-29

24. Clarke, C. F., Cheng, K., Frey, A. B., Stein, R., Hinds, W., Levine, A. J. 1988. Mol. Cell. Biol. 8: 1206-15

25. Collier, D. N., Bankaitis, V. A., Weiss, J. B., Bassford, P. J. 1988. Cell 53: 27383

26. Colman, A., Besley, J., Valle, G. 1982. J. Mol. Biol. 160: 459-72

27. Copeland, C. S., Doms, R. W., Bolzau, E. M., Webster, R. G., Helenius, A. 1986. J. Cell Biol. 103: 1179-91

28. Craig, E. A. 1988. Annu. Rev. Genet. 22: $631-77$

29. Craig, E. A. 1990. See Ref. 132a, pp. 301-22

30. Craig, E. A., Gross, C. A. 1991. Trends Biochem. Sci. 16: 135-40

31. Craig, E. A., Kramer, J., KosicSmithers, J. 1987. Proc. Natl. Acad. Sci. USA 84: 4156-60

32. Craig, E. A., Kramer, J., Shilling, J., Werner-Washburne, M., Holmes, S., et al. 1989. Mol. Cell Biol. 9: 3000-8

33. Creighton, T. E. 1990. Biochem. J. 270: 1-16

34. Creighton, T. E. 1991. Nature 352: 1718

35. Darnell, J., Lodish, H., Baltimore, D. 1986. Molecular Cell Biology, p. 137. New York: Freeman

36. Deshaies, R. J., Koch, B. D., Schekman, R. 1988. Trends Biochem. Sci. 13: 384-88

37. Deshaies, R. J., Koch, B. D., WernerWashburne, M., Craig, E. A., Schekman, R. 1988. Nature 332: 800-5

38. Dill, K. A. 1990. Biochemistry 29: $7135-55$

39. Dingwall, C., Laskey, R. A. 1990. Sem. Cell Biol. 1: 11-17

40. Dodson, M., McMacken, R., Echols, H. 1989. J. Biol. Chem. 264: 1071925
41. Doms, R., Keller, D., Helenius, A., Balch, W. 1987. J. Cell Biol. 105: 195769

42. Dorner, A. J., Bole, D. G., Kaufman, R. J. 1987. J. Cell Biol. 105: 2665-74

43. Echols, H. 1990. J. Biol. Chem. 265: 14697-14700

44. Eilers, M., Oppliger, W., Schatz, G. 1987. EMBO J. 6: 1073-77

45. Eilers, M., Schatz, G. 1986. Nature 322: 228-32

46. Ellis, R. J. 1987. Nature 328: 378-79

47. Ellis, R. J. 1990. Science 250: 954-59

48. Ellis, R. J. 1990. Sem. Cell Biol. 1: 1-9

49. Ellis, R. J., Van der Vies, A. 1991. Annu. Rev. Biochem. 60: 327 47

50. Deleted in proof

51. Fayet, O., Ziegelhoffer, T., Georgopoulos, C. 1989. J. Bacteriol. 171: 1379-85

52. Findlay, C. A., Hinds, P. W., Tan, T. H., Eliyahu, D., Oren, M., Levien, A. J. 1988. Mol. Cell. Biol. 8: 531-39

53. Fischer, G., Schmid, F. X. 1990. Biochemistry 29: 2206-12

54. Flaherty, K. M., DeLuca-Flaherty C., McKay D. B. 1990. Nature 346: 62328

55. Flaherty, K. M., McKay, D. B., Kabsch, W., Holmes, K. C. 1991. Proc. Natl. Acad. Sci. USA 88: 5041-45

56. Flajnik, M. E., Canel, C., Kramer, J., Kasahara, M. 1991. Proc. Natl. Acad. Sci. USA 88: 537-41

57. Flajnik, M. E., Canel, C., Kramer, J., Kasahara, M. 1991. Immunogenetics. In press

58. Flanagan, J. M., Kataoka, M., Sortie, D., Engelman, D. M. 1991. Proc. Natl. Acad. Sci. USA. In press

59. Deleted in proof

60. Flynn, G. C., Chappell, T. G., Rothman, J. E. 1989. Science 245: 385-90

61. Flynn, G. C., Rohl, J., Flocco, M. T., Rothman, J. E. 1991. Nature 353: 72630

62. Freedman, R. B. 1984. Trends. Biochem. Sci. 9: 438-41

63. Freedman, R. B. 1989. Cell 57: 1069 72

64. Freedman, R. B., Bulleid, N. J., Hawkins, H. C. Paver, J. K. 1989. Biochem. Soc. Symp. 55: 167-92

65. Gaitanaris, G. A., Papavassiliou, A. G., Rubock, P., Silverstein, S. J., Gottesman, M. E. 1990. Cell 61: 101320

66. Georgopoulos, C., Ang, D., Liberek, K., Zylicz, M. 1990. See Ref. 132a, pp.191-222

67. Georgopoulos, C. P., Hendrix, R. W., Casjens, S. R. Kaiser, A. D. 1973. J. Mol. Biol. 76: 45-60 
68. Gething, M. J., McCommon, K., Sambrook, J. 1986. Cell 46: 939-50

69. Goldenberg, D. P., King, J. 1981. $J$. Mol. Biol. 145: 633-51

70. Goldenberg, D. P., Smith, D. H., King, J. 1983. Proc. Natl. Acad. Sci. USA 80: 7060-64

71. Goloubinoff, P., Christeller, J. T., Gatenby, A. A., Lorimer, G. H. 1989. Nature 342: 884-89

72. Goloubinoff, P., Gatenby, A. A., Lorimer, G. H. 1989. Nature 337: 4447

73. Goodsell, D. S. 1991. Trends Biochem. Sci. 16: 203-6

74. Haas, I. G., Wabl, M. 1983. Nature 306: 387-89

75. Hardy, S. J., Randall, L. L. 1991. Science 251: $439-43$

76. Hartl, F.-U. 1991. Sem. Immunol. 3: 516

77. Hartl, F. U., Lecker, S., Schiebel, E., Hendrick, J. P., Wickner, W. 1990. Cell 63: 269-79

78. Hartl, F. U., Neupert W. 1990. Science 247: $930-38$

79. Hartl, F. U., Ostermann, J., Guiard, B., Neupert, W. 1987. Cell 51: 1027-37

80. Hartl, Г. U., Pfanner, N., Nicholson, D., Neupert, W. 1989. Biochim. Biophys. Acta 998: 1-45

81. Hartl, F. U., Schmidt, B., Wachter, E., Weiss, H., Neupert, W. 1986. Cell 47: 939-51

82. Hemmingsen, S. M., Ellis, R. J. 1986. Plant Physiol. 80: 269-76

83. Hemmingsen, S. M., Woolford, C., Van der Vies, S. M., Tilly, K., Dennis, D. T., et al. 1988. Nature 333: 330-34

84. Hendershot, L., Bole, D., Köhler, G., Kearney, J. F. 1987. J. Cell Biol. 104: $761-67$

85. Hendershot, L. M. 1990. J. Cell Biol. 111: 829-37

86. Hendrix, R. W. 1979. J. Mol.Biol. 129: 375-92

87. Hohn, T., Hohn, B., Engel, A., Wurtz, M. 1979. J. Mol. Biol. 129: 359-73

88. Horwich, A. L., Neupert, W., Hartl, F. U. 1990. Trends Biotechnol. 8: 126-31

89. Hurtley, S. M., Helenius, A. 1989. Annu. Rev. Cell Biol. 5: 277-307

90. Hurtley, S. M., Bole, D. G., HooverLitty, H., Helenius, A., Copeland, C. S. 1989. J. Cell Biol. 108: 2117-26

91. Hutchinson, E. G., Tichelaar, W., Hofhaus, G., Weiss, H., Leonard, K. R. 1989. EMBO J. 8: 1485-90

92. Jaenicke, R. 1987. Prog. Biophys. Mol. Biol. 49: 117-237

93. Jindahl, S., Dudani, A. K., Singh, B., Harley, C. B., Gupta, R. S. 1989. Mol. Cell Biol. 9: 2279-83
94. Kang, P. J., Ostermann, J., Shilling, J., Neupert, W., Craig, E. A., Pfanner, N. 1990. Nature 348: 137-43

95. Kassenbrock, C. K., Garcia, P. D., Walter, P., Kelly, R. B. 1988. Nature 333: $90-93$

96. Kassenbrock, C. K., Kelly, R. B. 1989. EMBO J. 8: $1461-67$

97. Kim, P. S., Baldwin, R. L. 1990. Annu. Rev. Biochem. 59: 631-60

98. Klausner, R. D., Lippincott-Schwartz, J., Bonifacino, J. S. 1990. Annu. Rev. Cell Biol. 6: 403-31

99. Deleted in proof

100. Kozutsumi, Y., Segal, M., Normington, K., Gething, M. J., Sambrook, J. 1988. Nature 332: $462-64$

101. Kusukawa, N., Yura, T., Ueguchi, C., Akiyama, Y., Ito, K. 1989. EMBO J8: 3517-21

102. Kuwajima, K. 1989. Proteins Struct. Funct. Genet. 6: 87-103

103. Laminet, A. A., Ziegelhoffer, T., Georgopoulos, C., Plückthun, A. 1990. EMBO J. 9: 2315-19

104. Landry, S. J., Gierasch, L. M. 1991. Biochemistry 30: 7359-62

105. Landry, S. J., Gierasch, L. M. 1991. Trends Biochem. Sci. 16: 159-63

106. Laskey, R. A., Honda, B. M., Mills, A. D., Finch, J. T. 1978. Nature 275: 41620

107. Lecker, S., Driessen, A. J. M., Wickner, W. 1990. EMBO J.9:2309-14

108. Lecker, S., Lill, R., Ziegelhoffer, T., Georgopoulos, C., Bassford, P. J., et al. 1989. EMBO J. 8: 2703-9

109. Lce, A. S. 1987. Trends Biochem. Sci. 12: $20-23$

110. Leustek, T., Dalie, B., Amir-Shapira, D., Brot, N., Weissbach, H. 1989. Proc. Natl. Acad. Sci. USA 86: 7805-8

111. Lewis, M. J., Pelham, H. R. B. 1985. EMBO J. 4: 3137-43

112. Liberek, K., Georgopoulos, C., Zylicz, M. 1988. Proc. Natl. Acad. Sci. USA 18: $6632-36$

113. Liberek, K., Marzzalek, J., Ang, D., Georgopoulos, C., Zylicz, M. 1991. Proc. Natl. Acad. Sci. USA 88: 287478

114. Lindquist, S., Craig, E. A. 1988. Annu. Rev. Genet. 22: 631-77

115. Lissin, N. M., Venyaminov, S. Yu., Girshovich, A. S. 1990. Nature 348: 339-42

116. Liu, G., Topping, T. B., Randall, L. L. 1989. Proc, Natl. Acad. Sci. USA 86: 9213-17

117. Lubben, T. H., Donaldson, G. K., Viitanen, P. V., Gatenby, A. A. 1989. Plant Cell 1: $1223-30$

118. Lubben, T. H., Gatenby, A. A., Don- 
aldson, G. K., Lorimer, G. H., Viitanen, P. V. 1990. Proc. Natl. Acad. Sci. USA 87: 7683-87

119. Luke, M. M., Sutton, A., Arndt, K. T. 1991. J. Cell Biol. 114: 623-38

120. Lyon, M. F. 1984. Cell 37: 621-28

121. Mahlke, K., Pfanner, N., Martin, J., Horwich, A. L., Hartl, F. U., Neupert, W. 1990. Eur. J. Biochem. 192: 551-55

122. Marshall, J. S., DeRocher, A. E., Keegstra, K., Vierling, E. 1990. Proc. Natl. Acad. Sci. USA 87: 374-78

123. Martin, J., Langer, T., Boteva, R., Schramel, A., Horwich, A. L., Hartl, F.-U. 1991. Nature 352: 36-42

124. Mascagni, P., Tonolo, M., Ball, H., Lim, M., Ellis, R. J., Coates, A. 1991. FEBS Lett. 286: 201-3

125. McMullin, T. W., Hallberg, R. L. 1987. Mol. Cell. Biol. 7: 4414-23

126. McMullin, T. W., Hallberg, R. L. 1988. Mol. Cell. Biol. 8: 371-80

127. Mendoza, J. A., Rogers, E., Lorimer, G. H., Horowitz, P. M. 1991. J. Biol. Chem. 266: 13044-49

128. Meyer, D. I. 1988. Trends Biochem. Sci. 13: $471-74$

129. Mitraki, A., Fane, B., Haase-Pettingell, C., Sturtevant, J., King, J. 1991. Science 253: $54-58$

130. Mitraki, A., King, J. 1989. Bio/Technology 7: 690-97

131. Mizzen, L. A., Chang, C., Garrels, J. I., Welch, W. J. 1989. J. Biol. Chem. 264: 20664-75

132. Morimoto, R. J., Milarski, K. L. 1990. See Ref. 132a, pp. 323-60

132a. Morimoto, R., Tissieres, A., Georgopoulos, C. eds. 1990. Stress Proteins in Biology and Medicine. Cold Spring Harbor, New York: Cold Spring Harbor Lab.

133. Morrison, S. L., Scharff, M. D. 1975. J. Immunol. 114: 655-59

134. Munro, S., Pelham, H. R. B. 1986. Cell 46: 291-300

135. Munro, S., Pelham, H. R. B. 1987. Cell 48: 899-907

136. Murakami, H., Pain, D., Blobel, G. 1988. J. Cell Biol. 107: 2051-57

137. Musgrove, J. E., Ellis, R. J. 1986. Philos. Trans. R. Soc. London Ser. B 313: 419-28

138. Musgrove, J. E., Johnson, R. A., Ellis, R. J. 1987. Eur. J. Biochem. 163: 52934

139. Neidhardt, F. C., van Bogelen, R. A. 1987. In Escherichia coli and Salmonella typhimurium. Cellular and Molecular Biology, ed. F. C. Neidhardt, J. L. Ingraham, K. B. Low, B. Magasanik, M. Schaechter, H. E. Umbarger, 2: 1334 45. Washington, DC: Am. Soc.
Microbiol.

140. Neidhardt, J. E., Phillips, T. A., van Bogelen, P. A., Smith, M. W., Georgalis, Y., Subramanian, A. R. 1981. $J$. Bacteriol. 145: 513-20

141. Neupert, W., Hartl, F. U., Craig, E., Pfanner, N. 1990. Cell 63: 447-50

142. Nicchitta, C. V., Blobel, G. 1990. Cell 60: 259-69

143. Normington, K., Kohno, K., Kozutsumi, Y., Gething, M. J., Sambrook, J. 1989. Cell 57: 1223-36

144. Ostermann, J., Horwich, A. L., Neupert, W., Hartl, F. U. 1989. Nature 341: 125-30

145. Ostermann, J., Voos, W., Kang, P. J., Craig, E. A., Neupert, W., Pfanner, N. 1991. FEBS Lett. 277: 281-84

146. Ostoa-Saloma, P., Ramirez, J., PerezMontfort, R. 1990. Biochim. Biophys. Acta 1041: 140-52

147. Palleros, D. R., Welch, W. J., Fink, A. L. 1991. Proc. Natl. Acad. Sci. USA 88: 5719-23

148. Pelham, H. R. B. 1986. Cell 46: 959-61

149. Pelham, H. R. B. 1988. Nature 332: 776-77

150. Pelham, H. R. B. 1990. See Ref. 132a, pp. 287-300

151. Pelham, H. R. B., Hardwick, K. G. Lewis, M. J. 1988. EMBO J. 7: 175762

152. Pfanner, N., Rassow, J., Guiard, B., Sollner, T., Hartl, F. U., Neupert W. 1990. J. Biol. Chem. 265: 16324-29

153. Pfanner, N., Tropschug, M., Neupert, W. 1987. Cell 49: 815-23

154. Phillips, G. J., Silhavy, T. J. 1990. Nature 344: 882-84

155. Pinhashi-Kimhi, O., Michalovitz, D., Ben-Zeev, A., Oren, M. 1986. Nature 320: $182-84$

156. Prasad, T. K., Hack, E., Hallberg, R. L. 1990. Mol. Cell. Biol. 10: 3979-86

157. Ptytsin, O. B. 1991. J. Protein Chem. 6: 272-93

158. Ptitsyn, O. B., Pain, R. H., Semisotnov, G. V., Zerownik, E. Razgulyaev, O. I. 1990. FEBS Lett. 262: 20-24

159. Pushkin, A. V., Tsuprun, V. L., Solovjeva Shubin, V. V., Evstigneeva, Z. G., Kretovich, W. L. 1982. Biochim. Biophys. Acta 704: 379-84

160. Randall, L. L., Hardy, S. J. S. 1986. Cell 46: 921-28

161. Randall, L. L., Hardy, S. J. S. 1989. Science 243: $1156-59$

162. Rassow, J., Guiard, B., Wienhues, U., Herzog, V., Hartl, F. U., Neupert, W. 1989. J. Cell Biol. 109: 1421-28

163. Rassow, J., Hartl, F. U., Guiard, B., Pfanner, N., Neupcrt, W. 1990. FEBS Lett. 275: 190-94 
164. Reading, D. S., Hallberg, R. L., Myers, A. M. 1989. Nature 337: 655-59

165. Rippmann, F., Taylor, W. R, Rothbard, J. B., Green, N. M. 1991. EMBO J. 10: 1053-59

166. Rose, M. D., Misra, L. M., Vogel, J. P. 1989. Cell 57: 1211-21

167. Rothblatt, J. A., Deshaies, R. J., Sanders, S. L., Daum, G., Schekman, R. 1989. J. Cell Biol. 109: 2641-52

168. Rothman, J. E. 1989. Cell 59: 591-601

169. Sachs, D. H., Schechter, A. N., Eastlake, A., Anfinsen, C. B. 1974. Nature 251: 242-44

170. Scherer, P. E., Krieg, U. C., Hwang, S. T., Vesteweber, D., Schatz, G. 1990. EMBO J. 9: 4315-22

171. Schlossman, D. M., Schmid, S. L., Braell, W. A., Rothman, J. E. 1984. $J$. Cell Biol. 99: 723-33

172. Schmid, S. L., Braell, W. A., Rothman, J. E. 1985. J. Biol. Chem. 260: 1005762

173. Schulz, G. E., Schirmer, R. H., Sachsenheimer, W., Pai, E. F. 1978. Nature 273: 120-24

174. Sell, S. M., Eisen, C., Ang, D., Zylicz, M., Georgopoulos, C. 1990. J. Bacteriol. 172: 4827-35

175. Semisotnov, G. V., Rodionova, N. A., Kutyshenko, V. P., Ebert, B., Blanck, J., Ptitsyn, O. B. 1987. FEBS Lett. 224: 9-13

176. Silver, L. M., Artzt, K., Bennett, D. 1979. Cell 17: 275-84

177. Skowyra, D., Georgopoulos, C., Zylicz, M. 1990. Cell 62: 939-44

178. Sternberg, N. 1973. J. Mol. Biol. 76: 25-44

179. Suzuki, C. K., Bonifacino, J. S., Lin, A. Y., Davis, M. M., Klausner, R. D. 1991. J. Cell Biol. 114: 189-205

180. Takano, T., Kakefuda, T. 1972. Nat. New Biol. 239: 34-37

181. Tandon, S., Horwitz, P. M. 1986, J. Biol. Chem. 261: 15615-81

182. Taniuchi, H. 1970. J. Biol. Chem. 245: 5459-68

183. Tilly, K., Murialdo, H., Georgopoulos, C. 1983. Proc. Natl. Acad. Sci. USA 78: 1629-33

184. Touchette, N. A., Perry, K. M., Matthews, C. R. 1986. Biochemistry 25: 5445-52

185. Trent, J., Nimmesgern, E., Wall, J. S., Hartl, F. U., Horwich, A. L. 1991. Nature. In press
186. Ursic, D., Ganetzky, B. 1988. Gene 68: 267-74

187. Ursic, D., Culbertson, M. R. 1991. Mol. Cell. Biol. I1: 2629-40

188. Van Dyk, T. K., Gatenby, A. A., LaRossa, R. A. 1989. Nature 324: 45153

189. Verner, K., Schatz, G. 1988. Science 241: 1307-13

190. Vestweber, D., Schatz, G. 1988. J. Cell Biol. 107: 2037-43

191. Viitanen, P. V., Donaldson, G. K., Lorimer, G. H., Lubben, T. H., Gatenby, A. A. 1991. Biochemistry 30: 971623

192. Viitanen, P. V., Lubben, T. H., Reed, J., Galoubinoff, P., O'Keefe, D. P., Lorimer, G. 1990. Biochemistry 29: 5665-71

193. Vogel, J. P., Misra, L. M., Rose, M. D. 1990. J. Cell Biol. 110: 1885-95

194. Waegemann, K., Paulsen, H., Soll, J. 1990. FEBS Lett. 261: 89-92

195. Wardinger, D., Eckerskorn, C., Lottspeich, F., Cleve, H. 1988. Biol. Chem. Hoppe-Seyler 369: 1185-89

196. Watanabe, M., Blobel, G. 1989. Cell 58: 695-705

197. Waxman, L., Goldberg, A. L. 1986. Science 232: 500-3

198. Welch, W. J. 1990. See Ref 132a, pp. $223 \cdot 78$

199. Welch, W. J., Feramisco, J. R. 1985. Mol. Cell Biol. 5: 1229-37

200. Wetlaufer, D. 1981. Adv. Protein Chem. 34: 61-92

201. Wetlaufer, D. B., Ristow, S. 1973. Annu. Rev. Biochem. 42: 135-58

202. Wickner, S., Hoskins, J., McKennly, K. 1991. Nature 350: 165-67

203. Wickner, W. T., Driessen, A., Hartl, F. U. 1990. Annu. Rev. Biochem. 60: 10124

204. Wienhues, U., Becker, K., Schleyer, M., Guiard, B., Tropschug, M., et al. 1991. J. Cell Biol. In press

205. Willson, K., Lewis, V., Zuckerman, K. S., Cordell, J., Dean, C., et al. 1989. Cell 57: 621-32

206. Zimmermann, R., Sagstetter, M., Lewis, M. J., Pelham, H. R. B. 1988. EMBO J. 7: 287580

207. Zylicz, M., LeBowitz, J. H., McMacken, R., Georgopoulos, C. 1983. Proc. Natl. Acad. Sci. USA 80: 6431-35 


\section{CONTENTS}

\section{PREFATORY}

Atomic and Nuclear Probes of Enzyme Systems, M. Cohn

\section{Structural Principles}

The Mechanism of $\alpha$-Helix Formation by Peptides, J. Martin Scholtz and Robert L. Baldwin

Solubilization and Functional Reconstitution of Biomembrane Components, John R. Silvius

Pathway Analysis of Protein Electron-Transfer Reactions, José Nelson Onuchic, David N. Beratan, Jay R. Winkler, and Harry B. Gray

StRUCTURE AND Function

Structure and Function of Actin, Wolfgang Kabsch and Joël Vandekerckhove

Approaching Atomic Resolution in Crystallography of Ribosomes, Ada Yonath

Rubisco: Structure and Mechanism, Gunter Schneider, Ylva Lindquist, and Carl-Ivar Brändén

Intramembrane Helix-Helix Association in Oligomerization and Transmembrane Signaling, B. J. Bormann and D. M. Engelman

The Permeation Pathway of Neurotransmitter-Gated Ion Channels, Henry A. Lester

Protein Folding in the Cell: The Role of Molecular Chaperones Hsp70 and Hsp60, F. U. Hartl, J. Martin, and W. Neupert

The Single-Nucleotide Addition Cycle in Transcription: A Biophysical and Biochemical Perspective, Dorothy A. Erie, Thomas D. Yager, and Peter H. von Hippel

Protein Involvement in Transmembrane Lipid Asymmetry,

Phillipe F. Devaux

Structure and Mechanism of Alkaline Phosphatase, Joseph E. Coleman 


\section{DYNAMICS}

Microtubule Dynamic Instability and GTP Hydrolysis, Harold $P$. Erickson and E. Timothy $O^{\prime}$ Brien

Femtosecond Biology, Jean-Louis Martin and Marten H. Vos

EMERGING TeCHNIQUeS

Solid-State NMR Approaches for Studying Membrane Protein Structure, Steven O. Smith and Olve B. Peersen

NMR Structure Determination in Solution: A Critique and Comparison with X-Ray Crystallography, Gerhard Wagner, Sven G. Hyberts, and Timothy F. Havel

Protein Folding Studied Using Hydrogen Exchange Labeling and Two-Dimensional NMR, $S$. Walter Englander and Leland Mayne

INDEXES

Subject Index 485 Cumulative Index of Contributing Authors, Volumes 17-21 496 Cumulative Index of Chapter Titles, Volumes 17-21 